\title{
Determinants of the continuous use of mobile apps: The mediating role of users awareness and the moderating role of customer focus
}

\author{
Qais Hammouri ${ }^{a^{*}}$, Jassim Ahmad Al-Gasawneh ${ }^{a}$, Emad Ahmad Abu-Shanab ${ }^{b}$, Nawras M. Nu- \\ sairat $^{\mathrm{a}}$ and Hakim Akhorshaideh ${ }^{\mathrm{c}}$
}

a Applied Science Private University, Jordan

${ }^{b}$ Qatar University, Doha, Qatar

${ }^{c}$ University of Jordan, Amman, Jordan

\section{H R O N I C L E}

Article history:

Received: March 10, 2021

Received in revised format: June

22, 2021

Accepted: July 25, 2021

Available online: July 25, 2021

Keywords:

Mobile Apps

Awareness

Continuous Use

Perceived Risk

Self-Efficacy

Social Influence

Customer Focus \begin{abstract}
A B S T R A C T
This research empirically explored the factors influencing the continuous use of mobile Apps in Jordan. The research utilized the Theory of Planned Behavior, the Diffusion of Innovation Theory and the Social Cognitive Theory to build the conceptual foundation of the research model. Using a quantitative approach, the study utilized a questionnaire with a set of well-validated items for the purpose of collecting data. The study collected 524 usable surveys, and analyzed the data using structural equation modeling technique (PLS-SEM). Results indicated that the three constructs relevant to this study (perceived risk, mobile self-efficacy, and social influence) were significant in predicting a users' awareness and the continuous use of mobile Apps. Customer focus moderated the relationship between awareness and continuous intention. In addition, the findings also confirm that users' awareness mediated the relationship between the three independent variables and the continuous use. The Detailed findings of this research are discussed, with conclusions and future research reported at the end.
\end{abstract}

\section{Introduction}

The quick surge in the number of smartphone users has dramatically influenced the expansion of mobile Apps usage. Mobile Apps are a vital part of our daily life, having facilitated daily human activities and meeting different needs in different areas. Globally, mobile Apps technology has become the dominant trend amongst mobile users in all fields. Such dominance comes due to the availability of Internet infrastructures and fierce competition among service providers, in addition to their role in meeting users' needs in a customized manner. Jordan is one of the developing countries that represents an example for a vastly growing community in the use of smartphones. Jordan's Telecom Regulatory Commission reported that in 2021, among the 10 million citizens of Jordan, eight million citizens are mobile users (Digital, 2021). Moreover, according to Statista.com, the use of mobile Apps amongst Jordanian citizens estimated 7.8 million Jordanian users in 2021 and it is expected to reach 8.3 million Jordanian users in 2025 (Statista.com, 2021a). Additionally, in the first quarter of 2021, the number of available Apps in Google Play Store reached 3.5 million applications, while the number of Apps in Apple Store included 2.22 million Apps (Statista.com, 2021b). Most mobile users have almost 20 Apps installed on their phones (Statista.com, 2021c). Furthermore, mobile users installed more than 200 billion Apps in 2020 (Mindsea.com, 2021). Even though the number of mobile Apps installed is huge, only $24 \%$ of such Apps are used only once and then instantly uninstalled (Clevertap.com,

* Corresponding author.

E-mail address: q alhammouri@asu.edu.jo (Q. Hammouri)

(C) 2021 by the authors; licensee Growing Science, Canada. doi: $10.5267 /$ j.ijdns.2021.7.014 
2021). Poor user awareness is one of the main reasons that drive mobile users to uninstall Apps. Other reasons include useless App's image, high storage allocation, excessive advertisements and notifications, incompatibility with device version, and privacy issues (Degirmenci, 2020; Ickin et al., 2017; Malik, 2020). Mobile Apps marketers are striving to improve customers' awareness to improve the level and intensity of their use (Mehra et al., 2020). Research related to mobile Apps recommended optimizing mobile Apps by informing users of what to do when they have questions, and how well they are doing by sending immediate feedback if they are using Apps correctly (Alessa et al., 2018; Elberzhager \& Holl, 2017; Mindsea.com, 2021). In addition, Apps' providers can offer users needed navigation cues to educate them on what to do for the best use practices.

The growing number of mobile Apps and users encountered a severe lack of studies examining the factors influencing the continuous use of mobile Apps. In addition, and within the context of Jordan, most of the studies concentrated on exploring the factors that might influence the behavioral intentions toward using mobile Apps for a specific context. Previous research explored the banking sector (Qasim \& Abu-Shanab, 2016), foods industry (Alalwan, 2020), governments (Hammouri \& AbuShanab, 2017), hotel and travel industry (Khwaldeh et al., 2020), learning and education (Hammouri \& Abu-Shanab, 2018), healthcare sector (Jarrad et al., 2021), and e-commerce (Al-maaitah et al., 2021; Al-Zagheer \& Barakat 2021; Hammouri et al., 2021b; Moh'd Al-Dwairi et al., 2018).

This study will investigate mobile Apps in general to improve our understanding of the impact of proposed factors on mobile users' behavior, rather than focusing on a specific area. Furthermore, we will try to examine the mediating role of users' awareness and the moderating role of customer focus on the continuous use of mobile Apps. According to the previous discussion, the main research question outlined in this study is: What are the predictors influencing the continuous use of mobile Apps?

The following section will present the theoretical background and the research model. Literature and conceptual view of the related work will be covered in the next section. The last section will cover data analysis and discussion followed by conclusion and future research.

\section{Theoretical Background}

Previous empirical studies have utilized technology adoption models to investigate how people are acting towards information technology. The scope emerged and generated several theories like the Theory of Reasoned Action (Fishbein \& Ajzen, 1977), Social Cognitive Theory (Bandura, 1982), Diffusion of Innovations (Rogers, 1975), Technology Acceptance Model (Davis, 1989), Theory of Planned Behavior (Ajzen, 1991), Unified Theory of Acceptance and Use of Technology (Venkatesh et al., 2003; Dwivedi et al., 2020). The primary objective of these theories was to understand the behavioral aspects of humans towards a new technology and investigate the factors affecting their intentions to adopt and use it.

Most previous studies included perceived risk as major negative predictor of users' behavioral intentions. Moreover, mobile self-efficacy was adopted from the Social Cognitive Theory (SCT) to understand the relationship between the capability of users and the technology adoption. In addition, Mobile user awareness was adopted from the Diffusion of Innovations Theory (DOI) to understand how mobile users' awareness influence the diffusion of a technology. Finally, social influence construct was adopted from the Theory of Planned Behavior (TPB), namely subjective norm, and was utilized by the UTAUT and UTAUT2 (Venkatesh et al., 2003 \& 2012).

This research adopted the four predictors based on their importance and contributions in previous classical theories (SCT, DOI, TPB, UTAUT, and UTAUT2). Research related to online applications included an additional construct, which relates to the expectations of users regarding the environment of e-business and its applications. The last extended predictor, which was included in many previous research studies, but was not included in the prior mentioned theories, is perceived risk. Perceived risk is a major predictor of technology adoption and a crucial factor that limits new technologies adoption (Hammouri et al., 2016; Elkhodr et al., 2021).

\subsection{Theoretical Framework and Hypotheses}

TAM is one of the famous theories used in the technology acceptance domain. Thousands of research studies investigated the TAM with different technologies and varied contexts. In addition, to the TAM, previous empirical research utilized the SCT, DOI, and the TPB to better understand the technology adoption domain and investigate the predictors of accepting a new technology (Alqahtani \& Kavakli-Thorne, 2020; Chen et al., 2018; De Santo \& Gaspoz, 2015; Halimi et al., 2021; Kim et al., 2019; Moh'd Al-Dwairi et al., 2018; Otieno et al., 2016).

The previous theories created a robust foundation for other classical models suggested afterwards for many reasons. Even though the previously mentioned theories are robust, still they are simple and parsimonious. Such simplicity necessitates extending them to accommodate different situations related to new technologies. The second reason is that the proposed models are appropriate for mobile Apps and do not need major adaptation effort. The third reason relates to the many studies attempting to replicate such models in different areas, where they yielded similar outcomes. Finally, the previously mentioned theories included robust predictors like social influence, where their role was approved by several classical theories afterwards. Based on such an argument, this study adopted the following research model shown in Fig. 1. 


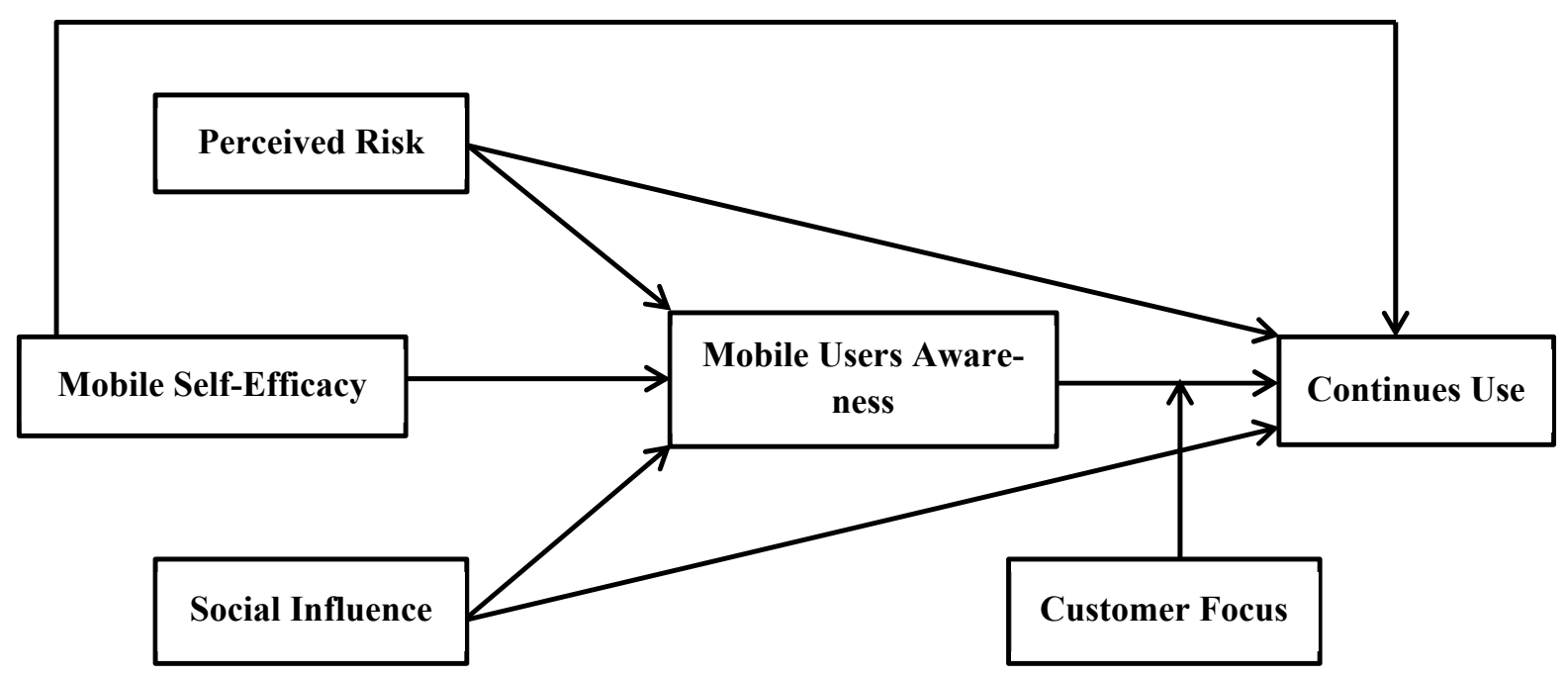

Fig. 1. Research Framework

The research model shown in Fig. 1 adopts a new perspective regarding the adoption of new technology. The continuous use of technology is a more suitable dependent variable as the majority of subjects sampled use multiple applications on their mobiles. Such conceptual construct fits better with the general use of applications more than a specific technology. The second important argument is the robustness of perceived ease of use and perceived usefulness in the TAM and TPB, where adding such constructs will dilute the variance and overcome the contribution of the proposed predictors. Based on that, the following sections will explore the context of research and the specific literature related to the set of hypotheses.

\subsection{Mobile Users' Awareness}

Awareness is a significant predictor of the decision to continue using mobile technology. Continuous use intention is widely used to measure the success of a new technology. In the domain of mobile Apps, most studies approved that awareness has a significant effect on the continuous use of mobile Apps (Al-Gasawneh \& Al-Adamat, 2020; Alqahtani \& Kavakli-Thorne, 2020; Saprikis et al., 2021; Wang \& Chou, 2016; Wei et al., 2020). Awareness of issues related to mobile Apps has a significant impact on the intention to install and use such Apps (Alshboul \& Streff, 2017). More specifically, awareness was found to be an influencing factor of the continuous use of mobile Apps (Baabdullah, 2020), where it leads to a positive perception of Apps and a significant intention to reuse (Hentzen et al., 2021). Mobile Apps awareness, conceptualized as "Know-how of mobile Apps installation", where users install Apps in line with their awareness of some issues like security considerations, privileges, compatibility, and license agreements. Empirically, research confirmed that when a mobile user is supported with the proper instructions and guidelines to install mobile Apps, such guidelines would positively influence his behavioral intention (Kamarudin et al., 2021; Shah et al., 2020; Sophus Lai \& Flensburg, 2020). Furthermore, mobile users prefer to know whether a mobile app might cause technical problems or security and privacy risks related to personal information (Elkhodr et al., 2021; Hammouri et al., 2016). Raising user's awareness regarding the benefits, potential threats, and how to install and configure a mobile app, will substantially enhance users' acceptance of such applications. It is crucial to inform users of the compatibility of the operating system with the Apps, where it supports users and enhances their continuous use in the future. Therefore, the following hypothesis is stated:

H1: Mobile users' awareness influences positively on the continuous use of mobile Apps.

\subsection{Perceived Risk}

Risk perception is one of the main challenges influencing the adoption of a technology. Even though mobile Apps marketers provide reliability and availability, risk is a primary issue, where it prevents the continuous use of Apps. Most of previous studies contended that risk issues in mobile Apps are crucial in defining users' perceptions, where they are framed in the following forms like security risk, privacy risk, device risk, psychological risk, performance risk, and financial risk (AbuShanab \& Ghaleb, 2012; Hawamleh et al., 2020). Moreover, perceived risk refers to the belief that all their personal information will not be exploited and lost (Al-Gasawneh et al., 2020; Dowling \& Staelin, 1994). In the context of mobile Apps, risk is conceptualized as a user's anticipation of exposing his/her private data when using mobile Apps (Abayomi et al., 2020). Users' risk recognition with respect to the Internet links to their risk recognition for mobile Apps. At the same time, it demonstrates users' uncertainty about loss or gain when using a specific App (Kamdjoug et al., 2021). Several empirical studies confirmed that if mobile users realize that the risks of installing and using a specific mobile App will be high, the likelihood 
of uninstalling an App will be high, and then the probability of their continuous use of that App will be low (Huan \& Hong, 2021; Mutahar et al., 2018; Thusi \& Maduku, 2020). Furthermore, other studies proclaimed that perceived risk will negatively influence the continuous use of mobile Apps (Akdur et al., 2020; Al-Natour et al., 2020; Yip \& Mo, 2020). Therefore, we hypothesize that:

$\mathbf{H}_{2}$ : Perceived risk has a negative influence on the continuous use of mobile Apps.

Hs: Perceived risk has a positive impact on mobile users' awareness.

Hs: Mobile users' awareness has a significant mediating role between perceived risk and the continuous use of mobile Apps.

\subsection{Mobile Self-Efficacy}

Self-efficacy is one of the main constructs proposed in the Social Cognitive Theory (Rojers, 1975). Several empirical studies utilized self-efficacy to understand the user's behavior in a wide range of technologies (Hammouri et al., 2021a; Huang \& Ren, 2020; Sala-González et al., 2021). Self-efficacy in mobile Apps context refers to the self-belief that a user can do functions with mobile Apps (Hammouri \& Abu-Shanab, 2020; Zhai \& Yu, 2020). Moreover, the concept of mobile self-efficacy is used to understand the awareness levels of mobile users toward some technical issues like potential threats and risks, availability, compatibility, and storage memory (Boutet \& Gambs, 2019; Tam et al., 2020). Therefore, individuals who are aware of mobile technology and the use of mobile Apps are described as being the most frequent users of mobile Apps. Such users are expected to continue adopting mobile technology based on their awareness levels (Menon et al., 2020; Samoggia \& Riedel, 2020). On the other hand, several studies reported that the lack of knowledge in mobile technology is a major threat to the continuous adoption of mobile Apps (Huang \& Ren, 2020; Wei et al., 2020). Such studies assert that the lack of awareness among mobile users will result in lower use behavior (Byambasuren et al., 2019). Hence, we hypothesized that:

$\mathbf{H}_{3}$ : Mobile self-efficacy has a positive influence on the continuous use of mobile Apps.

H6: Mobile self-efficacy has a positive influence on mobile users' awareness.

H9: Mobile user's awareness mediates the relationship between mobile self-efficacy and continuous use.

\subsection{Social Influence}

Social influence (SI) is one of the most important constructs in the Theory of Planned Behavior (TPB). Social influence refers to the extent to which an individual believes that other people should participate, use, and participate in some activities (Abu Shanab et al., 2010). The UTAUT proposed social influence as an integrated construct from subjective norms, extrinsic motivation and other constructs from other theories. Social influence is described as "the degree to which an individual perceives importance that others believe he or she should use the new system" (Venkatesh et al., 2003, p: 426). Several empirical studies confirmed that social influence has a significant effect on the continuous use intentions (Cheng et al., 2020; Hong, 2019; Lai \& Zhao, 2019; Noor et al., 2020). In mobile Apps context, social influence describes the degree to which a user believes that peers think he/she should use mobile Apps. Flache et al., (2017) classified social influence into two categories. The first category is external sources like mass media reports and users' experiences. The second category is the set of interpersonal social influences, which includes the positive or negative word of mouth from friends, family members, and colleagues who download and use different mobile Apps. Social influence is considered as a major factor affecting users' intention toward using mobile Apps. Social influence is one of the most important elements that influence online social support. Thus, mobile apps providers should thrive to improve the social influence through sharing users' experiences and provide the technical guidance to improve the awareness of mobile users through enabling them to download and use mobile Apps in a safe manner (Hammouri et al., 2016). In this study, we assume that social influence is the degree to which a user believes that others are aware of the related issues to mobile Apps download (Dinev \& Hu, 2007; Verkasalo et al., 2010). Therefore, we state the following hypotheses:

H4: Social Influence has a positive influence on the continuous use of mobile Apps.

H7: Social influence has a positive influence on mobile users' awareness.

H10: Mobile user's awareness mediates the relationship between social influence and continuous use.

\subsection{Moderating Role of Customer Focus}

Customer focus is one of the most powerful strategies utilized by marketers to meet customer expectations and improve their satisfaction (Madhani et al., 2020). Most organizations are striving to achieve a successful customer relationship through providing a customer-focused structure, reward system culture, and policy (Lee \& Lee, 2020). Through the accomplishment of such a relationship, a service provider becomes central to its most lucrative users. Additionally, the path to build a strong 
customer relationship entails a strong customer-centric focus and the unceasing provision of superior products/services in addition to added value to these targeted key customers via personalized/customized offerings (Papaioannou et al., 2018). Professionals and marketers are recommended to implement several tactics to build an effective customer focus strategy, such tips include encourage users to collaborate, make a user feel heard, make a customer know where they are, and utilize feedback from users (Islamgaleyev et al., 2020; Madrakhimova, 2021). Several studies reported that user focus exerts differential impact through direct or indirect relationships on the continuous use of mobile Apps depending on the awareness of the Apps issues like risk and compatibility issues (Kayyali et al., 2017; Sezgin et al., 2017; Pai \& Alathur, 2019). This insight provides weight to the idea that customer focus may represent a condition that moderates the effect on the relationship between mobile user awareness and continuous use, rather it is considered as a predictor of continuous use. Empirical research found that customer focus strategy influences the continuous use of mobile Apps (Behnam et al., 2020; Li et al., 2021). In the case of high levels of awareness, users may be able to use a specific mobile App effectively and enjoy feelings of trust and confidence in using such App (Dandis et al., 2021; Ngah et al., 2021). These feelings may drive users to create a positive electronic word of mouth toward a specific App. Furthermore, because users' satisfaction is the key success factor to expand the regular use of Apps, customer focus will make users recommend, use and install an App. In the case of low customer focus, users may lack the awareness to use Apps. Thus, customers with negative focus are more likely to uninstall the App and provide negative feedback toward using such App. Hence:

\section{H11: The relationship between mobile user awareness and continuous use is moderated by customer focus.}

\section{Research Methodology}

This study adopted a quantitative approach to understand the relationships mapped in the research model, and to investigate the major predictors of the continuous use of mobile Apps by Jordanian users. The study utilized a questionnaire to collect data from the research subjects. In line with the purpose of this research, the primary objective of this questionnaire is to probe the subject's opinion regarding the different variables included in the research model. This research presumes that the continuous use of mobile Apps is affected by five constructs (shown in the study research model shown in Fig. 1). The questionnaire is the main data collection instrument for collecting the research primary data, where it was designed in Arabic language and contained two parts. The first part focused on the demographic information of mobile users, which included: gender, age and education. The second part includes the items utilized for measuring the six factors included in the study. The main goal is to understand the major variables affecting mobile users' behavior to continue using mobile Apps. The survey utilized 12 items measuring the three independent variables as follows: perceived risk (6 items, selected from Al-Natour et al. (2020)), mobile self-efficacy (3 items, adopted from Huang and Ren (2020)), social influence (3 items, were selected from Noor et al., (2020)) and were they revised to fit the context of mobile Apps. The survey also included three items to measure the mediation variable (mobile user awareness), which were utilized from Alqahtani and Kavakli-Thorne (2020). Moreover, five items measured the moderating variable (key customer focus, selected from Kim et al. (2004)). Finally, the survey included three items measuring the continuous use of mobile Apps, where they were selected from Baabdullah (2020). The survey items were reworded and adapted to the study context whenever deemed necessary. All the items of the research constructs were measured using a fivepoint Likert scale ranging from 1 (strongly disagree) to 5 (strongly agree). Dodge (2020) reported that when a research team designs their study, they must verify that their work will precisely represent the population in which they are studying. Therefore, the target population for this research comprises users of smartphones in Jordan. The questionnaire was used as an instrument to explore the perceptions of a random sample from mobile users in Jordan. A total of 533 electronic questionnaires were received, a total of 9 responses were excluded because of severe empty responses. Thus, the total number of valid surveys was 524. The collected data were keyed into the SmartPLS 3.0 software. Table 1 shows the demographic information of the sample.

Table 1

Sample Demographic

\begin{tabular}{cccc}
\hline Measure & Category & Count & Percentage \% \\
\hline \multirow{2}{*}{ Age } & $18-25$ & 209 & 39.8 \\
& $26-33$ & 167 & 31.8 \\
& $34-41$ & 88 & 16.7 \\
& Age $>41$ & 60 & 11.7 \\
\hline \multirow{2}{*}{ Education } & Secondary & 33 & 6.4 \\
& Diploma & 61 & 11.6 \\
& Bachelor & 370 & 70.6 \\
\hline \multirow{2}{*}{ Gender } & Postgraduate & 60 & 11.4 \\
& Male & 246 & 46.9 \\
\hline
\end{tabular}




\section{Data Analysis and Results}

Based on the structure of the research model, a structural equation modeling technique is the easiest statistical method to test such set of relationships. The study utilized SmartPLS as a tool for testing the research model and to answer the research question.

\subsection{Measurement Model}

Perceived risk, mobile self-efficiency, social impact, mobile user awareness, continuous intention, and key customer focus are the five first order factors in this study. Perceived risk, mobile self-efficacy, social influence, mobile user awareness, continuous intention, and main customer focus were all reflective variables in the evaluation. The factor loadings (FL), composite reliability (CR), and the average variance extracted (AVE), were calculated using the repeated indicator methodology. The measurement model was evaluated using convergent validity and discriminant validity. The CR, AVE and FLs were all examined as part of the convergent validity of the study. As a result, the numbers shown in Table 2 related to the AVE and CR statistics were both above the required threshold (more than 0.50 and 0.70 respectively). Heterotrait-Monotraint (HTMT) assesses the model's discriminant validity (Henseler, 2015), and all the obtained HTMT values in this investigation were less than 0.90 , with values ranging from 0.075 to 0.848 . Table 3 summarizes the findings. As a result, each latent construct measurement in this investigation was entirely discriminant against each other, according to Henseler et al. (2015).

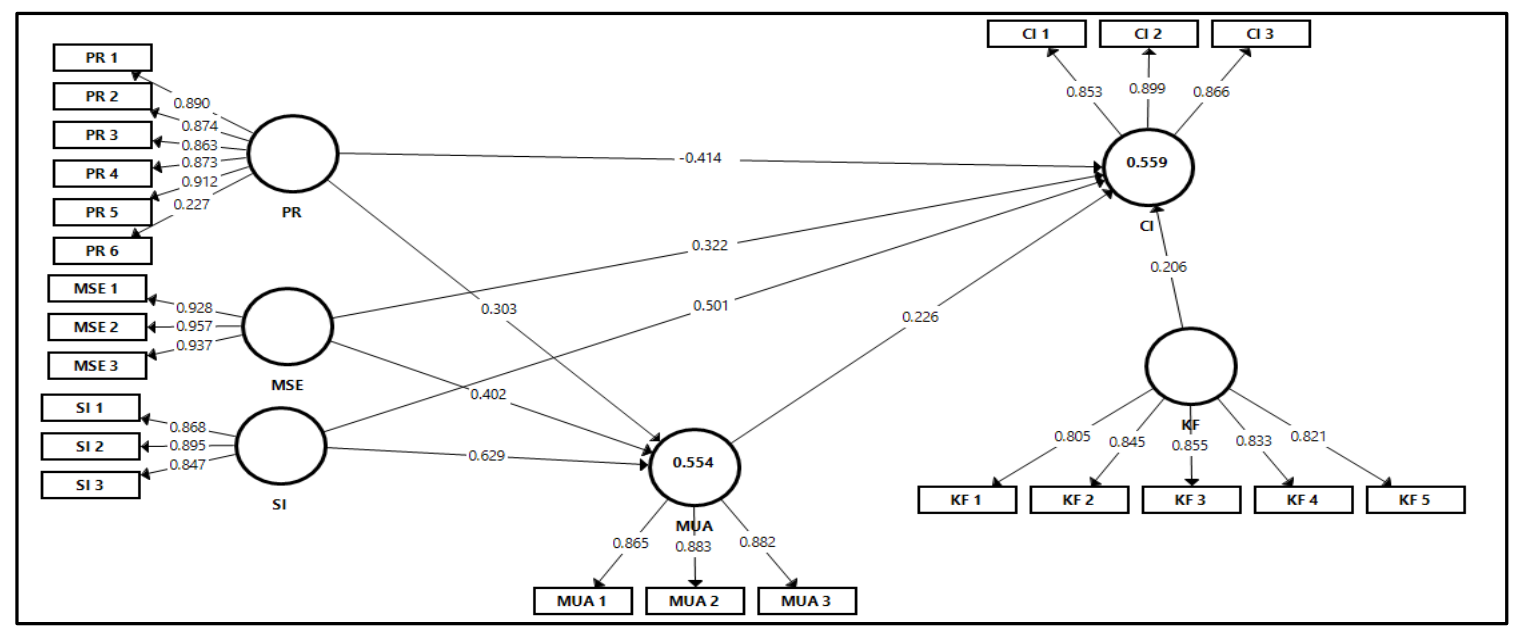

Fig. 2. Measurnment Model

Table 2

Factor Loadings and Construct Validity and Reliability

\begin{tabular}{|c|c|c|c|c|}
\hline Constructs & Code & Factor Loadings & Composite Reliability & AVE \\
\hline \multirow{6}{*}{ Perceived Risk } & PR 1 & 0.890 & \multirow{6}{*}{0.874} & \multirow{6}{*}{0.634} \\
\hline & PR 2 & 0.874 & & \\
\hline & PR 3 & 0.863 & & \\
\hline & PR 4 & 0.873 & & \\
\hline & PR 5 & 0.912 & & \\
\hline & PR 6 & 0.227 & & \\
\hline \multirow{3}{*}{ Mobile Self-Efficacy } & MSE 1 & 0.928 & \multirow{3}{*}{0.833} & \multirow{3}{*}{0.626} \\
\hline & MSE 2 & 0.957 & & \\
\hline & MSE 3 & 0.937 & & \\
\hline \multirow{3}{*}{ Social Influence } & SI 1 & 0.868 & \multirow{3}{*}{0.881} & \multirow{3}{*}{0.650} \\
\hline & SI 2 & 0.895 & & \\
\hline & SI 3 & 0.847 & & \\
\hline \multirow{3}{*}{ Mobile User Awareness } & MUA 1 & 0.928 & \multirow{3}{*}{0.833} & \multirow{3}{*}{0.626} \\
\hline & MUA 2 & 0.957 & & \\
\hline & MUA 3 & 0.937 & & \\
\hline \multirow{3}{*}{ Continuous Use } & CI 1 & 0.853 & \multirow{3}{*}{0.940} & \multirow{3}{*}{0.759} \\
\hline & CI 2 & 0.899 & & \\
\hline & $\mathrm{CI} 3$ & 0.866 & & \\
\hline \multirow{5}{*}{ Key Customer Focus } & KF 1 & 0.805 & \multirow{5}{*}{0.841} & \multirow{5}{*}{0.692} \\
\hline & KF 2 & 0.845 & & \\
\hline & KF 3 & 0.855 & & \\
\hline & KF 4 & 0.833 & & \\
\hline & $\mathrm{KF} 5$ & 0.821 & & \\
\hline
\end{tabular}


Table 3

HTMT

\begin{tabular}{|c|c|c|c|c|c|c|}
\hline & CI & KF & MSE & MUA & PR & SI \\
\hline \multicolumn{7}{|l|}{ Continuous Intention (CI) } \\
\hline Key Customer Focus (KF) & 0.721 & & & & & \\
\hline Mobile Self-Efficacy (MSE) & 0.170 & 0.123 & & & & \\
\hline Mobile User Awareness (MUA) & 0.681 & 0.596 & 0.081 & & & \\
\hline Perceived Risk (PR) & 0.799 & 0.768 & 0.429 & 0.634 & & \\
\hline Social Influence (SI) & 0.638 & 0.611 & 0.075 & 0.848 & 0.682 & \\
\hline
\end{tabular}

\subsection{Structural Model and Hypotheses Testing}

\subsubsection{Hypothesized Direct Effects of the Constructs in the Structural Model}

As shown in Table 4, the achieved coefficient of determination $\mathrm{R}^{2}$ values for MUA and CI were 0.60 and 0.676 respectively. Such results indicate that the explained variances in MUA and CI are $60 \%$ and $67.6 \%$ respectively. This result is acceptable according to Chin's suggested cut-off point of 0.19 (Chin, 1998). As a result, the predictors are adequately explaining the variance in the predicted construct. Furthermore, the $\mathrm{Q}^{2}$ value associated with $\mathrm{CI}$ was 0.310 , which is much higher than zero, confirming the validity of Chin's predictive model criterion (Chin, 2010). Such a result confirms the model's acceptability. Similarly, the model demonstrated a high level of predictive significance. The VIF values were 1,163 and 3.101, respectively, and are lower than 5 (as suggested by Hair et al., (2016).

Table 4

Hypothesized Direct Effects in the Structural Model

\begin{tabular}{|c|c|c|c|c|c|c|c|c|c|}
\hline & Path & St, $\beta$ & St. d & $\mathrm{R}^{2}$ & $\mathrm{Q}^{2}$ & $\mathrm{~F}^{2}$ & VIF & T-value & P-value \\
\hline H1 & $\mathrm{MUA} \rightarrow \mathrm{CI}$ & 0.226 & 0.041 & & & 0.588 & 2.213 & 5.512 & 0.001 \\
\hline $\mathrm{H} 2$ & $\mathrm{PR} \rightarrow \mathrm{CI}$ & -0.414 & 0.123 & 0.676 & 0.310 & 0.051 & 1,828 & 3.365 & 0.000 \\
\hline H3 & $\mathrm{MSE} \rightarrow \mathrm{CI}$ & 0.322 & 0.080 & & & 0.270 & 1.179 & 4.025 & 0.002 \\
\hline $\mathrm{H} 4$ & $\mathrm{SI} \rightarrow \mathrm{CI}$ & 0.501 & 0.142 & & & 0.037 & 2.633 & 3.528 & 0.001 \\
\hline H5 & $\mathrm{PR} \rightarrow \mathrm{MUA}$ & 0.303 & 0.095 & & & 0.123 & 1,163 & 3.189 & 0.003 \\
\hline H6 & $\mathrm{MSE} \rightarrow \mathrm{MUA}$ & 0.402 & 0.101 & 0.600 & & 0.119 & 2.576 & 3.980 & 0.000 \\
\hline $\mathrm{H} 7$ & SI × MUA & 0.629 & 0.133 & & & 0.087 & 3.101 & 4.729 & 0.000 \\
\hline
\end{tabular}

The direct predictors of CI (i.e. MUA, PR, MSE, and SI) were all significant with a $\mathrm{p}$ value less than the required value by most social sciences references (p-values were 0.001 , less than $0.001,0.002$, and 0.001 respectively). These numbers illustrate that the absolute p-values of 0.01 and 0.05 can be used to predict the outcomes. In addition, the estimated standard betas values for MUA, PR, MSE, and SI when associated with CI, were $0.226,-0.414,0.322$, and 0.501 respectively, where they represent substantial correlation values. As a result, the associations are positive, and hypotheses $\mathrm{H} 1, \mathrm{H} 2, \mathrm{H} 3$, and $\mathrm{H} 4$ were supported. Still, H2 yielded a negative path coefficient, but was not supported. Finally, the path coefficient values for PR, MSE, and SI when associated with MUA were all significant with a p-value less than 0.05 (The p values were $0.003,0.000$, and 0.000 respectively). The beta values for MUA prediction were $0.303,0.402$, and 0.629 respectively. Such results confirm and support H5, H6, and $\mathrm{H} 7$.

\subsubsection{Indirect Effect of the Constructs}

According to the Bootstrapping technique employed to estimate the indirect effects, the results in Table 5 indicate that three relationships were significant. The findings revealed that there was a statistically significant mediation effect. As a result, hypotheses H8, H9, and H10 were found to be supported (See Fig. 3).

Table 5

Mediating Effect of Mobile User Awareness

\begin{tabular}{cccccccc}
\hline & PATH SHAPE & St. $\beta$ & St. d & T values & $2.50 \%$ & $97.50 \%$ & p-values \\
\hline H8 & PR $\rightarrow$ MUA $\rightarrow$ CI & 0.137 & 0.061 & 2.245 & 0.032 & 0.0132 & 0.036 \\
H9 & MSE $\rightarrow$ MUA $\rightarrow$ CI & 0.071 & 0.033 & 2.151 & 0.041 & 0.111 & 0.004 \\
H10 & SI $\rightarrow$ MUA $\rightarrow$ CI & 0.142 & 0.049 & 2.897 & 0.089 & 0.127 & 0.002 \\
\hline
\end{tabular}




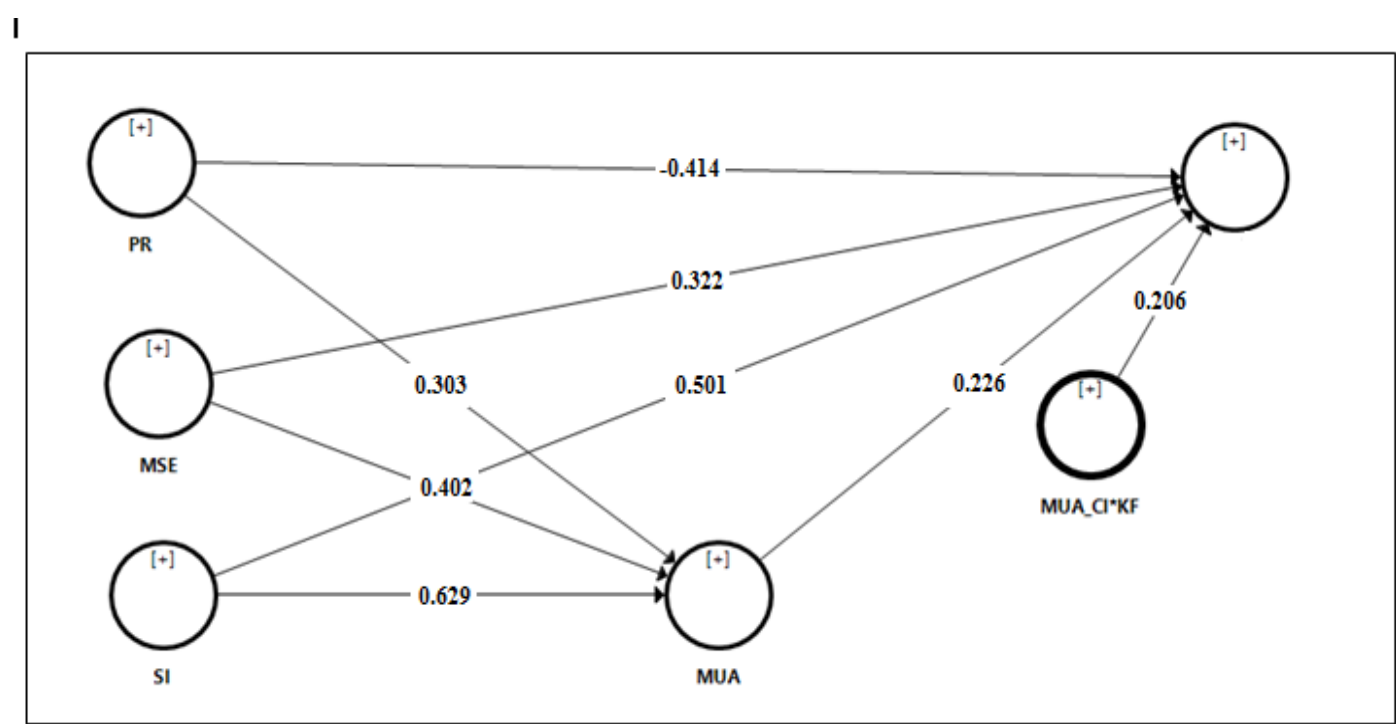

Fig. 3. Hypotheses Testing

\subsubsection{Moderating Effect}

The results of the test related to the moderation influence of key customer focus (KF) on the relationship between the effect of MUA and the CI indicated a significant influence, where the influence changes with the levels of KF. Figure 4 depicts the influence as the lines are not parallel. The data revealed that the association between MUA and CI is moderated by KF, which supports H11 (St. B=0.206, t-value = 3.029; P-value = 0.004)

Table 6

Moderating Effect

\begin{tabular}{cccccccc}
\hline & Path & St, $\beta$ & St. d & $F^{2}$ & VIF & T-value & P-value \\
\hline H11 & MUA-CI * KF & 0.206 & 0.068 & 0.062 & 2.325 & 3.029 & 0.004 \\
\hline
\end{tabular}

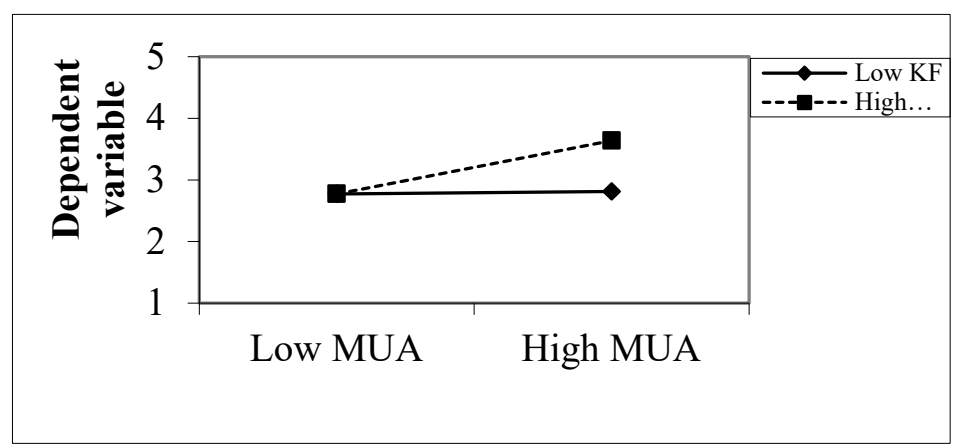

Fig. 4. Moderating Effect Plot

\section{Discussion}

The main contribution of this study is to understand better the factors influencing the adoption (continuous use) of mobile Apps. Based on that, this study proposed a few predictors (independent factors: perceived risk, mobile self-efficacy and social influence) to see their influence on the dependent variable (the continuous use of mobile Apps). In addition, this study shed more light on the influence of mobile user awareness and customer focus as mediating and moderating factors. The proposed research model imported such a set of variables from previous theories like TAM, TPB, and DOT. The findings of this study are centered on four main conclusions. First, MUA was a significant predictor of the continuous use of mobile Apps (H1 was supported). Such results confirm previous reported literature (Kamarudin et al., 2021; Shah et al., 2020; Sophus Lai \& Flensburg, 2020). The significant and positive relationship between MUA and CI indicates that issues related to mobile Apps technology like security and privacy, compatibility and system storage are crucial for the adoption of such Apps. This indicates that if mobile users have a good perception of such issues, they will most likely be confident and reinforce their intention to continue using the Apps. 
In addition, results showed a negative relationship between perceived risks and the continuous use (H2 was supported). Such finding is consistent with previous studies reported (Akdur et al., 2020; Al-Natour et al., 2020; Yip \& Mo, 2020). Furthermore, the results also indicate the higher the perception of risk for a specific App, the less users are expected to use such App. MSE was found to be a predictor of users' intention to use mobile Apps (H3 was supported). This finding is in alignment with previous research conducted by Hammouri and Abu-Shanab (2020) and Zhai and Yu (2020). The positive significant impact between MSE and CI indicates that mobile users in Jordan apprehend that a user who has sufficient knowledge in mobile technology and keeps up to date with such technology will have a higher intention to use the Apps. Looking at the structural model in Table 4, SI has the highest beta value among other predictors (H4 was supported). This result concurs with previous studies reported (Cheng et al., 2020; Hong, 2019; Lai \& Zhao, 2019; Noor et al., 2020). The positive significant relationship between SI and CI indicates that mobile users in Jordan tend to listen to their peers' experiences before using or installing mobile Apps.

Second, PR, MSE and SI were significant predictors of MUA (H5, H6 and H7 were supported). The significant relationship between PR and MUA indicates that mobile users realize that if they were equipped with the necessary knowledge about the risks expected from the use of a specific App, they will be more aware about the risk issues generated from using or installing such App. Such finding concurs with previous reported studies (Huan \& Hong, 2021; Mutahar et al., 2018; Thusi \& Maduku, 2020). The positive and significant relationship between MSE and MUA indicates that a user who has a good knowledge in mobile technology like security and privacy issues; would likely be more confident, less anxious, and would enjoy the use of mobile Apps. The finding follows reported studies conducted by Menon et al. (2020), and Samoggia and Riedel (2020). SI has the highest beta value among the other predictors to MUA. The significant relationship between SI and MUA indicates that mobile users tend to share their experiences about a specific App whether positive like availability, credibility, usefulness and ease of use, or negative like uncertainty, threats and financial loss. Such shared experiences will influence the level of awareness among their peers. This finding is aligned with the results reported by previous research (Dinev \& Hu, 2007; Verkasalo et al., 2010).

Third, the findings indicate that MUA mediated the relationship between the independent variables (PR, MSE, and SI) and the dependent variable (CI). Therefore, H8, H9 and H10 were supported. In addition, the results indicate that the differences in awareness levels of mobile users may be explained in part by the differences in how users perceive their risk issues, the adequate knowledge of mobile technology, and the tendency to listen to peers' experiences. Awareness is one of the most important factors influencing users' perception of a specific App and drives their intention to the continuous usage of such App. The availability of information, instructions, and guidelines can therefore serve in minimizing the levels of ambiguity for users regarding Apps.

Finally, customer focus significantly influenced the relationship between users' awareness of Apps and their continuous use, thereby supporting H11. Customer focus can lower perceptions of uncertainty and ambiguity of Apps; it also improves the levels of awareness and know-how for users. Therefore, such a path leads to building a trusted and secure perception of users regarding Apps, which ultimately drives them to continue using the Apps. This finding is in alignment with the results reported by Behnam et al., (2020) and Li et al., (2021).

\section{Conclusions and future research}

The results of such research emphasized the importance of perceived risk, mobile self-efficacy and social influence as powerful factors in forming users' perceptions and driving their intentions toward the continuous use of mobile Apps. In addition, User awareness plays a vital role in predicting the continuous use of mobile Apps. Such an element plays an interactive mediating role in the relationship between the independent variables (perceived risk, mobile self-efficacy, and social influence) and the dependent variable (continuous usage). Moreover, customer focus is found to be a moderator on the relationship between user awareness and continuous use.

\subsection{Research Implications and Contributions}

This study is the first to adopt such interrelated constructs from three major theories. In addition, the study offers a set of contributions that improve our understanding of the domain. Theoretically, the current study demonstrated solid evidence on the applicability of the extended model and the integration of the three different theories (TPB, DOI and SCT). It provides a genuine perspective by adopting an innovative approach toward a mediation influence (by user's awareness) and a moderation influence (by customer focus). Such a perspective is well discussed and linked to previous research. The study also supported previously fragmented relationships while integrating them in one model. The research findings reinforced the existing limited empirical studies on users' intentions to continue using mobile Apps. This study is the first to be reported (up to the knowledge of the authors) that explore such context in developing countries, like Jordan. Thus, carrying out this study in Jordan adds to its novelty and contribution to the scientific community. From a practical perspective, the study findings are helpful for mobile Apps developers, where they need to focus on how they can improve users' awareness to influence their continuous use intentions. This is usually explained by the focus on awareness mediating role in driving the continuous use of mobile Apps 
context, which is facilitated by the enhancement of users' awareness through customer focus strategy. Developers and businesses are also required to concentrate on customer focus strategy to benefit from the intertwined influence of users' awareness and their usage behavior.

\subsection{Limitations and Future Work}

Like many other empirical studies, the current research suffers from few limitations. First, this research was limited to mobile users in Jordan, where a response from a valid sample of mobile users was utilized to examine the suggested hypotheses. Such local samples might limit the generalizability of the results. This could be solved by using a more randomly selected sample of respondents and exploring a multinational set of samples. Moreover, since this research focuses on understanding the mediation role of awareness on the relationship between (PR, MSE and SI) and the continuous use of mobile Apps, it would be interesting to consider the mediating role of electronic word of mouth (EWOM) in such a context. Users are influenced by their peers' word-of-mouth and especially with the spread of social media.

\section{References}

Abayomi, O. J., Zhang, X., Peng, X., \& Zhao, S. (2020). How Do Institutional Pressures and Behavioral Intentions Affect Mobile Services Adoption? The Moderating Role of Perceived Risk. ACM SIGMIS Database: the DATABASE for Advances in Information Systems, 51(2), 82-100.

Abu-Shanab, E., \& Ghaleb, O. (2012). Adoption of mobile commerce technology: An involvement of trust and risk concerns. International Journal of Technology Diffusion (IJTD), 3(2), 36-49.

AbuShanab, E., Pearson, J. M., \& Setterstrom, A. J. (2010). Internet banking and customers' acceptance in Jordan: The unified model's perspective. Communications of the Association for Information Systems, 26(1), 23.

Ajzen, I. (1991). The theory of planned behavior. Organizational Behavior and Human Decision Processes, 50(2), $179-211$.

Akdur, G., Aydin, M. N., \& Akdur, G. (2020). Adoption of Mobile Health Apps in Dietetic Practice: Case Study of Diyetkolik. JMIR mHealth and uHealth, 8(10), e16911.

Alalwan, A. A. (2020). Mobile food ordering apps: An empirical study of the factors affecting customer e-satisfaction and continued intention to reuse. International Journal of Information Management, 50, 28-44.

Alessa, T., Abdi, S., Hawley, M. S., \& de Witte, L. (2018). Mobile apps to support the self-management of hypertension: systematic review of effectiveness, usability, and user satisfaction. JMIR mHealth and uHealth, 6(7), e10723.

Al-Gasawneh, J. A., \& Al-Adamat, A. M. (2020). The relationship between perceived destination image, social media interaction and travel intentions relating to Neom city. Academy of Strategic Management Journal, 19(2), 1-12.

Al-Gasawneh, J., Al-Wadi, M., Al-Wadi, B., Alown, B. \& Nuseirat, N. (2020). The Interaction Effect of Comprehensiveness Between Social media and Online Purchasing Intention in Jordanian Pharmacies. International Association of Online Engineering. Retrieved October 13, 2020 from https:/www.learntechlib.org/p/217794/

Al-maaitah, T. A., Majali, T. E., Alsoud, M., \& Al-maaitah, D. A. (2021). The Impact of COVID-19 on the Electronic Commerce Users Behavior. Journal of Contemporary Issues in Business and Government, 27(1), 784-793.

Al-Natour, S., Cavusoglu, H., Benbasat, I., \& Aleem, U. (2020). An Empirical Investigation of the Antecedents and Consequences of Privacy Uncertainty in the Context of Mobile Apps. Information Systems Research, 31(4), 1037-1063.

Alqahtani, H., \& Kavakli-Thorne, M. (2020, February). Factors Affecting Acceptance of a Mobile Augmented Reality Application for Cybersecurity Awareness. In Proceedings of the 2020 4th International Conference on Virtual and Augmented Reality Simulations (pp. 18-26).

Alshboul, Y., \& Streff, K. (2017, December). Beyond cybersecurity awareness: Antecedents and satisfaction. In Proceedings of the 2017 International Conference on Software and e-Business (pp. 85-91).

Al-Zagheer, H., \& Barakat, S. (2021). E-Recruitment as Application Solution during Corona Pandemic. Annals of the Romanian Society for Cell Biology, 25(2), 5051-5058.

Baabdullah, A. M. (2020). Factors influencing adoption of mobile social network games (M-SNGs): The role of awareness. Information Systems Frontiers, 22(2), 411-427.

Bandura, A. (1982). Self-efficacy mechanism in human agency. American Psychologist, 37(2), 122.

Behnam, M., Sato, M., Baker, B. J., Delshab, V., \& Winand, M. (2020). Connecting customer knowledge management and intention to use sport services through psychological involvement, commitment, and customer perceived value. Journal of Sport Management, 34(6), 591-603.

Boutet, A., \& Gambs, S. (2019, November). Inspect What Your Location History Reveals About You: Raising user awareness on privacy threats associated with disclosing his location data. In Proceedings of the 28th ACM International Conference on Information and Knowledge Management (pp. 2861-2864).

Byambasuren, O., Beller, E., \& Glasziou, P. (2019). Current knowledge and adoption of mobile health apps among Australian general practitioners: survey study. JMIR mHealth and uHealth, 7(6), e13199.

Chen, G., Luo, C., \& Xu, H. (2018). Understanding Usage Intention of Social Media's Innovative Functions: Based on Expanded Innovation Diffusion Theory.

Cheng, Y., Sharma, S., Sharma, P., \& Kulathunga, K. M. M. C. B. (2020). Role of personalization in continuous use intention of Mobile news apps in India: Extending the UTAUT2 model. Information, 11(1), 33. 
Clevertap.com (2021). https://clevertap.com/blog/customer-experience-optimization. Accessed by the Internet in (21 May, 2021)

Dandis, A. O., Wright, L. T., Wallace-Williams, D. M., Mukattash, I., Al Haj Eid, M., \& Cai, H. (2021). Enhancing consumers' self-reported loyalty intentions in Islamic Banks: The relationship between service quality and the mediating role of customer satisfaction. Cogent Business \& Management, 8(1), 1892256.

Davis, F. D. (1989). Perceived usefulness, perceived ease of use, and user acceptance of information technology. MIS Quarterly, 13(3), 319-340.

De Santo, A., \& Gaspoz, C. (2015). Influence of users' privacy risks literacy on the intention to install a mobile application. In New contributions in information systems and technologies (pp. 329-341). Springer, Cham.

Degirmenci, K. (2020). Mobile users' information privacy concerns and the role of app permission requests. International Journal of Information Management, 50, 261-272.

Digital (2021). https://datareportal.com/reports/digital-2021-jordan. Accessed by the Internet in (21 May, 2021)

Dinev, T., \& Hu, Q. (2007). The centrality of awareness in the formation of user behavioral intention toward protective information technologies. Journal of the Association for Information Systems, 8(7), 23.

Dodge, K. A. (2020). Annual Research Review: Universal and targeted strategies for assigning interventions to achieve population impact. Journal of Child Psychology and Psychiatry, 61(3), 255-267.

Dowling, G. R., \& Staelin, R. (1994). A model of perceived risk and intended risk-handling activity. Journal of Consumer Research, 21(1), 119-134.

Dwivedi, Y. K., Rana, N. P., Tamilmani, K., \& Raman, R. (2020). A meta-analysis based modified unified theory of acceptance and use of technology (meta-UTAUT): a review of emerging literature. Current Opinion in Psychology, 36, 1318.

Elberzhager, F., \& Holl, K. (2017). Towards automated capturing and processing of user feedback for optimizing mobile apps. Procedia Computer Science, 110, 215-221.

Elkhodr, M., Mubin, O., Iftikhar, Z., Masood, M., Alsinglawi, B., Shahid, S., \& Alnajjar, F. (2021). Technology, Privacy, and User Opinions of COVID-19 Mobile Apps for Contact Tracing: Systematic Search and Content Analysis. Journal of Medical Internet Research, 23(2), e23467.

Fishbein, M., \& Ajzen, I. (1977). Belief, attitude, intention, and behavior: An introduction to theory and research.

Flache, A., Mäs, M., Feliciani, T., Chattoe-Brown, E., Deffuant, G., Huet, S., \& Lorenz, J. (2017). Models of social influence: Towards the next frontiers. Journal of Artificial Societies and Social Simulation, 20(4).

Halimi, F. F., Gabarre, S., Rahi, S., Al-Gasawneh, J. A., \& Ngah, A. H. (2021). Modelling Muslims' revisit intention of nonhalal certified restaurants in Malaysia. Journal of Islamic Marketing.

Hammouri, Q. M., Abu-Shanab, E. A., \& Nusairat, N. M. (2021a). Attitudes Toward Implementing E-Government in Health Insurance Administration. International Journal of Electronic Government Research (IJEGR), 17(2), 1-18.

Hammouri, Q., \& Abu-Shanab, E. (2017). Exploring the factors influencing employees' satisfaction toward e-tax systems. International Journal of Public Sector Performance Management, 3(2), 169-190.

Hammouri, Q., \& Abu-Shanab, E. (2018). Exploring factors affecting users' satisfaction toward E-learning systems. International Journal of Information and Communication Technology Education (IJICTE), 14(1), 44-57.

Hammouri, Q., \& Abu-Shanab, E. A. (2020). Major Factors Influencing the Adoption of Cloud Computing in Jordan. International Journal of Technology and Human Interaction (IJTHI), 16(4), 55-69.

Hammouri, Q., Abu-Shanab, E., \& Manasrah, A. (2016). Examining the Impact of Privacy, Security and Law on Trust in Mobile Computing. Saba Journal Of information Technology And Networking (SJITN)-ISSN: 2312-4989, 4(1).

Hammouri, Q., Al-Gasawneh, J. A., Nusairat, N. M., Hanandeh, A., \& Barakat, S. (2021b). The Determinants of Trust and its Influence on Online Buying Intention: An Empirical Study on Social Commerce in Jordan. Annals of the Romanian Society for Cell Biology, 25(5), 4522-4539.

Hawamleh, A. M. A., Alorfi, A. S. M., Al-Gasawneh, J. A., \& Al-Rawashdeh, G. (2020). Cyber Security and Ethical Hacking: The Importance of Protecting User Data. Solid State Technology, 63(5), 7894-7899.

Henseler, J., Ringle, C. M., \& Sarstedt, M. (2015). A new criterion for assessing discriminant validity in variance-based structural equation modeling. Journal of the Academy of Marketing Science, 43(1), 115-135.

Hentzen, J. K., Hoffmann, A. O., \& Dolan, R. M. (2021). Which consumers are more likely to adopt a retirement app and how does it explain mobile technology-enabled retirement engagement?. International Journal of Consumer Studies.

Hong, I. B. (2019). Understanding and predicting behavioral intention to adopt mobile banking: The korean experience. Journal of Global Information Management (JGIM), 27(3), 182-202.

Huan, L., \& Hong, Z. (2021). A study of purchase intention in mobile devices based on takeaway apps. Management Review, 33(2), 207.

Huang, G., \& Ren, Y. (2020). Linking technological functions of fitness mobile apps with continuance usage among Chinese users: Moderating role of exercise self-efficacy. Computers in Human Behavior, 103, 151-160.

Ickin, S., Petersen, K., \& Gonzalez-Huerta, J. (2017, June). Why do users install and delete Apps? A survey study. In International Conference of Software Business (pp. 186-191). Springer, Cham.

Islamgaleyev, A., Petrova, M., Kurenkeyeva, G., Shalbayeva, S., \& Kadirbergenova, A. (2020). Increasing customer focus in metal trading. Entrepreneurship and Sustainability Issues, 8(1), 604.

Jarrad, A. A., Joudeh, J. M., Mukattash, I. L., \& Hassouneh, A. G. (2021). The effect of multidimensional service quality on word of mouth in university on-campus healthcare centers. The TQM Journal. 
Kamarudin, S., Omar, S. Z., Zaremohzzabieh, Z., Bolong, J., \& Osman, M. N. (2021). Factors Predicting the Adoption of EGovernment Services in Telecenters in Rural Areas: The Mediating Role of Trust. Asia-Pacific Social Science Review, 21(1).

Kamdjoug, J. R. K., Wamba-Taguimdje, S. L., Wamba, S. F., \& Kake, I. B. E. (2021). Determining factors and impacts of the intention to adopt mobile banking app in Cameroon: Case of SARA by afriland First Bank. Journal of Retailing and Consumer Services, 61, 102509.

Kayyali, R., Peletidi, A., Ismail, M., Hashim, Z., Bandeira, P., \& Bonnah, J. (2017). Awareness and use of mHealth apps: a study from England. Pharmacy, 5(2), 33.

Khwaldeh, S., Alkhawaldeh, R. S., Masa'deh, R. E., AlHadid, I., \& Alrowwad, A. A. (2020). The impact of mobile hotel reservation system on continuous intention to use in Jordan. Tourism and Hospitality Research, 20(3), 358-371.

Kim, J. W., Choi, J., Qualls, W., \& Park, J. (2004). The impact of CRM on firm-andrelationship-level performance in distributed networks. Communications of the Association for Information Systems, 14(1), 30.

Kim, M. J., Lee, C. K., \& Contractor, N. S. (2019). Seniors' usage of mobile social network sites: Applying theories of innovation diffusion and uses and gratifications. Computers in Human Behavior, 90, 60-73.

Lai, W., \& Zhao, L. (2019). Exploring the Influencing Factors of Undergraduates' Continuance Intentions in e-Reading APPs (EIFUCIEA). International Journal of Information and Education Technology, 9(12).

Lee, S. M., \& Lee, D. (2020). "Untact": a new customer service strategy in the digital age. Service Business, 14(1), 1-22.

Li, M. L., Lin, S. P., Chan, Y. H., \& Wu, C. H. (2021). Customer Involvement Facets Stimulating Customers' Intention to Use Internet-Only Bank Services in China: The Extension of Perceived Risk-Value Model. Journal of Organizational and End User Computing (JOEUC), 33(5), 74-97.

Madhani, P. M. (2020). Building a Customer Focused Strategy: Developing Conceptual Frameworks and Research Propositions. SCMS Journal of Indian Management, 17(3), 5-25.

Madrakhimova, M. S. (2021). Customer-oriented approach as a development strategy of a tourism enterprise. Middle European Scientific Bulletin, 12, 311-314.

Malik, R. (2020). To understand the life cycle and customer adoption of mobile apps in modern India. International Journal of Electronic Customer Relationship Management, 12(3), 273-290.

Mehra, A., Paul, J., \& Kaurav, R. P. S. (2020). Determinants of mobile apps adoption among young adults: Theoretical extension and analysis. Journal of Marketing Communications, 1-29.

Menon, D., Chandrasekhar, M., Kosztin, D., \& Steinhoff, D. C. (2020). Impact of mobile technology-based physics curriculum on preservice elementary teachers' technology self-efficacy. Science Education, 104(2), 252-289.

Mindsea.com (2021). https://mindsea.com/app-stats/. Accessed by the Internet in (21 May, 2021)

Moh'd Al-Dwairi, R., Al-Shraideh, L. M., \& Abu-Shanab, E. A. (2018). Mobile commerce adoption from consumers perspective: the case of Jordan. International Journal of Information Systems and Social Change (IJISSC), 9(2), 12-27.

Mutahar, A. M., Daud, N. M., Ramayah, T., Isaac, O., \& Aldholay, A. H. (2018). The effect of awareness and perceived risk on the technology acceptance model (TAM): mobile banking in Yemen. International Journal of Services and Standards, 12(2), 180-204.

Ngah, A. H., Gabarre, S., Han, H., Rahi, S., Al-Gasawneh, J. A., \& Park, S. H. (2021). Intention to purchase halal cosmetics: do males and females differ? A multigroup analysis. Cosmetics, 8(1), 19.

Noor, N. M., Noranee, S., Zakaria, M. F., Unin, N., \& Suaee, M. A. H. M. (2020, February). Online Shopping: The Influence of Attitude, Subjective Norm and Perceived Behavioral Control on Purchase Intention. In Proceedings of the 2020 The 6th International Conference on E-Business and Applications (pp. 33-36).

Pai, R. R., \& Alathur, S. (2019). Assessing awareness and use of mobile phone technology for health and wellness: Insights from India. Health Policy and Technology, 8(3), 221-227.

Papaioannou, A., Kriemadis, T., Kapetaniou, P., Yfantidou, G., \& Kourtesopoulou, A. (2018). Customer oriented strategy and business performance in tourism and hospitality industry. In Innovative Approaches to Tourism and Leisure (pp. 417432). Springer, Cham.

Otieno, O. C., Liyala, S., Odongo, B. C., \& Abeka, S. O. (2016). Theory of reasoned action as an underpinning to technological innovation adoption studies. World Journal of Computer Application and Technology, 4(1), 1-7.

Qasim, H., \& Abu-Shanab, E. (2016). Drivers of mobile payment acceptance: The impact of network externalities. Information Systems Frontiers, 18(5), 1021-1034.

Rogers, R. W. (1975). A protection motivation theory of fear appeals and attitude change1. The Journal of Psychology, 91(1), 93-114.

Sala-González, M., Pérez-Jover, V., Guilabert, M., \& Mira, J. J. (2021). Mobile apps for helping informal caregivers: a systematic review. International Journal of Environmental Research and Public Health, 18(4), 1702.

Samoggia, A., \& Riedel, B. (2020). Assessment of nutrition-focused mobile apps' influence on consumers' healthy food behaviour and nutrition knowledge. Food Research International, 128, 108766.

Saprikis, V., Avlogiaris, G., \& Katarachia, A. (2021). Determinants of the Intention to Adopt Mobile Augmented Reality Apps in Shopping Malls among University Students. Journal of Theoretical and Applied Electronic Commerce Research, 16(3), 491-512.

Sezgin, E., Özkan-Yildirim, S., \& Yildirim, S. (2017). Investigation of physicians' awareness and use of mHealth apps: a mixed method study. Health Policy and Technology, 6(3), 251-267. 
Shah, A. M., Yan, X., Shah, S. A. A., \& Ali, M. (2020). Customers' perceived value and dining choice through mobile apps in Indonesia. Asia Pacific Journal of Marketing and Logistics, 33(1), 1-28.

Sophus Lai, S., \& Flensburg, S. (2020). A proxy for privacy uncovering the surveillance ecology of mobile apps. Big Data \& Society, 7(2), 2053951720942543.

Statista.com (2021a). https://www.statista.com/forecasts/1145545/mobile-internet-users-in-jordan. Accessed by the Internet in (21 May, 2021)

Statista.com (2021b). https://www.statista.com/statistics/267309/number-of-apps-on-mobile-phones/. Accessed by the Internet in (21 May, 2021)

Statista.com (2021c). https://www.statista.com/statistics/289418/number-of-available-apps-in-the-google-play-storequarter/. Accessed by the Internet in (21 May, 2021)

Tam, C., Santos, D., \& Oliveira, T. (2020). Exploring the influential factors of continuance intention to use mobile Apps: Extending the expectation confirmation model. Information Systems Frontiers, 22(1), 243-257.

Thusi, P., \& Maduku, D. K. (2020). South African millennials' acceptance and use of retail mobile banking apps: An integrated perspective. Computers in Human Behavior, 111, 106405.

Venkatesh, V., Morris, M. G., Davis, G. B., \& Davis, F. D. (2003). User acceptance of information technology: Toward a unified view. MIS Quarterly, 27(3), 425-478.

Venkatesh, V., L. Thong, J. Y., \& Xu, X. (2012). Consumer Acceptance and Use of Information Technology: Extending The Unified Theory of Acceptance and Use of Technology. MIS Quarterly, 36(1), 157-178.

Verkasalo, H., López-Nicolás, C., Molina-Castillo, F. J., \& Bouwman, H. (2010). Analysis of users and non-users of smartphone applications. Telematics and Informatics, 27(3), 242-255.

Wang, E. S. T., \& Chou, N. P. Y. (2016). Examining social influence factors affecting consumer continuous usage intention for mobile social networking applications. International Journal of Mobile Communications, 14(1), 43-55.

Wei, J., Vinnikova, A., Lu, L., \& Xu, J. (2020). Understanding and predicting the adoption of fitness mobile apps: Evidence from China. Health communication, 1-12.

Yip, W. S., \& Mo, W. Y. (2020). An Investigation of Purchase Intention of Using Mobile Apps for Online Traveling and Booking Service. International Journal of Innovation, Management and Technology, 11(2).

Zhai, Y., \& Yu, W. (2020). A Mobile App for Diabetes Management: Impact on Self-Efficacy Among Patients with Type 2 Diabetes at a Community Hospital. Medical Science Monitor: International Medical Journal of Experimental and Clinical Research, 26, e926719-1. 


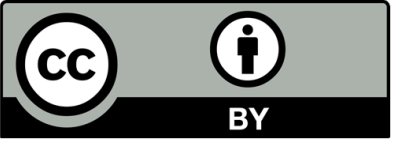

C 2021 by the authors; licensee Growing Science, Canada. This is an open access article distributed under the terms and conditions of the Creative Commons Attribution (CC-BY) license (http://creativecommons.org/licenses/by/4.0/). 